MARTA GIEC

Państwowa Wyższa Szkoła Filmowa, Telewizyjna i Teatralna im. Leona Schillera

\section{Przekształcanie pamięci. Found footage jak machina kulturowej reinterpretacji}

Materiał archiwalny, zapis dokumentalnych wydarzeń na taśmie celuloidowej, reportażowa rejestracja wydarzeń historycznych. To główne narzędzia, które w trakcie drugiej wojny światowej i tuż po niej otworzyły nieskończone możliwości manipulacji wątkiem znalezionym w celu sterowania opinią publiczną. Posługiwanie się techniką kolażu materiału pochodzącego $\mathrm{z}$ różnych źródeł w odniesieniu do filmu jako spadkobiercy fotografii było znane już przed wojną, jednak dopiero od lat 40., dzięki rozbudowanym strategiom montażowym, rozwinął się właściwy found footage. Twórcy śmielej podeszli do zagadnienia rekontekstualizacji gotowych wypowiedzi audiowizualnych, dostrzegając tym samym możliwości płynące $\mathrm{z}$ metaforycznych oraz formalnych jakości w przeciwieństwie do banalnych scen, oczywistych rozwiązań obrazowych. Istotna okazała się spuścizna takich twórców, jak René Clair, Hans Richter czy Walter Ruttman. Jednak prawdziwym kamieniem milowym w dziedzinie wtórnego operowania obrazem dokumentalnym okazała się działalność Esther Shub, Dżigi Wiertowa i Jorisa Ivensa. Ich wypowiedzi filmowe prezentują skalibrowane na nowo sceny z politycznie napiętnowanych materiałów, nadając im tym samym odmienne znaczenie. Posiłkowali się oni materiałami odrzuconymi przez kroniki filmowe i źródłami bardziej marginalnymi[1].

Proliferowanie technologii filmowej zarówno w produkcjach zinstytucjonalizowanych, jak i niezależnych oraz rozkwit dominujących praktyk filmotwórczych lat 6o., takich jak direct cinema czy cinéma-vérité, nieco wyciszył zainteresowanie found footage wśród artystów skłaniających się ku formom bardziej dokumentalnym. Również przekształcenia kulturowe i społeczne miały wpływ na to, że filmowcy zaczęli z lekkim sprzętem rejestracyjnym podchodzić bezpośrednio bliżej człowieka i otaczających go zdarzeń zamiast posiłkować się gotowymi materiałami kronikarskimi.

Inaczej rzecz się miała $\mathrm{z}$ artystycznie ukonstytuowanym found footage. Możliwości tej techniki odkrył już na początku lat 6o. Stan Vanderbeek, jeden z czołowych twórców filmowej awangardy amerykańskiej okresu powojennego. Styl towarzyszący pracom Vanderbeeka od początku jego działalności charakteryzował się soczystą, pełną obrazowej
Sens odnaleziony
Images

vol. XVII/no. 26

Poznań 2015

ISSN 1731-450x

\title{
Sens odnaleziony
}


dynamiki mieszanką technologii oraz gatunków. Ze względu na silny nacisk, jaki autor kładł na walor estetyczny i kompozycyjny swoich filmów, skłaniałabym się bardziej do określenia go mianem artysty buntownika aniżeli zaangażowanego społecznie filmowca doby nowego dokumentu, rodzącej się wraz z takimi systemami, jak Sony Portapak ery wideo.

Twórczość Vanderbeeka stanowi idealne wprowadzenie do diachronicznie kształtującego się found footage. Formy, które rozwinął reżyser, stanowią zadziwiającą mieszankę technologii i medialnych zapośredniczeń. Jego formy znalezione to często collage’owe animacje transponujące materiał znalezionej fotografii reklamowej, gazetowej na poklatkowo rejestrowane animacje zespalane dalej w montażu z fragmentami filmów z różnych źródeł oraz własnymi rejestracjami filmowymi. Tego rodzaju kompozycje stanowiły bogaty bukiet inspiracji dla następców Vanderbeeka, jak na przykład Terry’ego Gilliama, odpowiedzialnego za animacje w serii Latający cyrk Monty Pythona. Więź estetyczna oraz żartobliwy wydźwięk prac obu artystów stanowi dowód na procesualność historyczną pewnych tendencji twórczych, które nie odciskają się piętnem oczywistości na doświadczeniu widza. Prawie zawsze nieświadomy tych proweniencji odbiorca będzie odczuwał podskórnie, że ten rodzaj wizualnej reprezentacji jest powiązany z czymś, co zaistniało w przeszłości. Teza ta jest kusząca tym bardziej, że zespół cech ideowych stojących za filmami Vanderbeeka, jakimi jest satyra polityczna, czarny humor, groteska, silnie koresponduje z przekazem stojącym za animacjami Gilliama.

Eksperymentalny duch miłośnika stymulujących fantasmagorii filmowych, przyświecający Vanderbeekowi, oraz narzędzie rozrywki i niezobowiązującego przerywnika w transmisji, jakim były animacje Gilliama, to na pierwszy rzut oka niepozorne wytwory z peryferii filmu. $\mathrm{W}$ istocie to silne narzędzie krytyki społecznej oraz łamania przyzwyczajeń odbiorczych widzów przywykłych do schematycznych form opowiadania oraz propagandowych (nawet w dzisiejszych czasach) narzędzi perswazji.

Gilles Deleuze w swych rozważaniach o powojennym kinie wskazuje między innymi na pewną istotną zmianę, która towarzyszy rozwojowi świadomości widza wraz z ewolucją języka kinematografii. Byłaby to świadomość klisz, które nieustannie napotyka widz. Klisze należy w tym układzie rozumieć jako „obrazy standardowe, które wypełniają ikonosferę współczesnej kultury”[2]. Owa świadomość klisz ma silny związek z potępieniem fabuły jako następstwem trwania odbiorców audiowizualnych bodźców w epoce obrazu-akcji, skorelowanym z multiplikowanymi obrazami nieskończenie rozszczepiającymi się gatunkowo lub podgatunkowo na nowe, przyswajane w ogromnym tempie przekazy.

W takim habitacie wytwarza się idealny mikroklimat dla multimedialnych działań wykraczających poza obszary nieświadomości odbiorczej, filmowego undergroundu i wdzierających się do nurtu

[2] M. Jakubowska, Teoria kina Gillesa Deleuze’a,

Rabid, Kraków 2003, s. 153. 
współczesnej multigatunkowości obrazów, którą przewidział Deleuze. Found footage XXI wieku to źródło kulturowego fermentu, spoiwo między starym a nowym przekazem wizualnym oraz estetyczna stymulacja łączenia technik i zaskakujących metod montażowych, w dobie, w której - wydawałoby się - nic już nie jest w stanie widza zadziwić.

Film Billa Morrisona Light Is Calling (2004) to przykład opatrzonego niezwykłą wrażliwością, zmysłem estetycznym oraz szacunkiem dla dawnej kinematografii found footage. Autor - wykorzystując znaleziony materiał filmowy, dobierając do niego muzykę oraz szereg zabiegów realizatorskich wyznaczających linię odczytania dzieła - stworzył film niepowtarzalny w swej kruchości, medytacyjnej intensywności i zarazem uproszczonej treści.

Punktem wyjścia we wnikliwym wglądzie w Light Is Calling byłoby przyjrzenie się jego historycznemu pierwowzorowi. Morrison w wykorzystanym przez siebie materiale użył fragmentu jednej sceny $\mathrm{z}$ niemego filmu The Bells Jamesa Younga $\mathrm{z}$ roku 1926. Treścią fabularnego wydarzenia była konna podróż przez las, jaką wraz ze swoimi kompanami odbywał umundurowany milicjant. Na swojej drodze napotkali podążający w tym samym kierunku wóz z sianem. Po krótkiej chwili milicjant odkrywa, że w stogu ukrywa się młoda, atrakcyjna kobieta, która doskonale się bawi, na zmianę wychylając się i chowając pod sianem. Kierowca powozu nie zauważa, że kobieta w pewnym momencie $\mathrm{z}$ niego wypada, i jedzie dalej. Milicjant zatrzymuje swoją drużynę, zsiada z konia i pomagając kobiecie wstać z ziemi, zaprasza ją gestem, by skorzystała $z$ jego pomocy. Kobieta z początku waha się, ale przystaje na propozycję i do pobliskiego miasteczka zostaje odeskortowana przez milicjanta jako pasażer.

Przytoczony wyżej fragment filmu to zaledwie wycinek pełnego metrażu Younga, który dla współczesnego widza, podążającego śladem całości opowiadania uposażonego w mnogość bohaterów i scen, stanowi umykający pamięci element, mający za zadanie napędzenie akcji, nadanie jej nowego biegu (z punktu widzenia budowy dramaturgicznej można by było uznać go za punkt zwrotny filmu - pierwsze spotkanie protagonistów). Morrison wynosi jednak ten krótki fragment do rangi dzieła sztuki samego w sobie, składając jednocześnie hołd - anachronicznym z dzisiejszej perspektywy - zabiegom filmowym oddającym tak ulotny i jakże trudny do zobrazowania, nawet w dzisiejszych czasach rozwiniętej gramatyki filmowej, moment spotkania przyszłych kochanków, któremu towarzyszy pierwszy promień uczucia. Przedwojenny widz, doświadczając sceny spotkania w lesie, zapewne przeżywał los młodej kobiety i przystojnego milicjanta, domyślając się, że jest świadkiem rodzącego się uczucia. Tego rodzaju scena w filmie wywoływała ogromne poruszenie i wyznaczała dalszy los bohaterów, o którym widzowie rozmawiali i pamiętali jeszcze długo po projekcji.

Morrison przywołał unikatową wartość w swoim filmie, zapraszając współczesnego widza do przeżycia tego emocjonującego 
momentu na nowo, w odmienionej formie. Zakupił zniszczoną taśmę z filmem, dokonał optycznego skanu materiału i przemontował wybraną scenę, wycinając towarzyszące jej perypetie, ograniczając się do momentu spotkania i wspólnego odjazdu. Młody reżyser odważył się przedefiniować plastykę zdewaluowanego obrazu, opatrzywszy ją dodatkowo efektem morfującej z każdą następującą na ekranie klatką emulsji fotograficznej. Powstały obraz w zestawieniu z nostalgiczną muzyką Michaela Gordona stanowi wzruszającą formę medytacyjną, gdzie postaci, skryte za pięknymi uszkodzeniami materiału filmowego, zdają się płynąć jakby w odmęcie bezczasu, a nie w tyranii poszczególnych klatek przewijających się na ząbkowaniu projektora szesnaście razy na sekundę. Za warstwami płynnych zniekształceń skryte są oblicza dawnych aktorów, zapomnianych postaci, przestarzałych inscenizacji, a mimo to w obrazie Morrisona są oni dogłębnie prawdziwi, miejscami zatracając podobne ludziom oblicza, zdające zmieniać się płynnie w głowy szkieletów, modeli fotografii post-mortem. W dalszym odczytaniu emocjonalnym Light Is Calling emanuje smutkiem, tęsknotą, nieuchronnością przemijania, co w zestawieniu $\mathrm{z}$ dawnym materiałem filmowym stanowi interesującą refleksję nad czasem, jego wymiarami i pamięcią. Warto w tym miejscu przywołać słowa Deleuze’a, który zagadnieniu pamięci w swej teorii przeznaczył specjalne miejsce:

Między przeszłością, jako pre-egzystencją jako taką, a teraźniejszością jako nieskończenie skurczoną przeszłością, znajdują się zatem wszystkie kręgi przeszłości, stanowiące wiele rejonów, złóż, pokładów, rozciągniętych, albo też skurczonych; każdy zaś rejon ma swe własne cechy, swe zabarwienia, swe aspekty, swe wyjątkowości, swe połyskliwe punkty, swe dominanty[3].

W filmie Light Is Calling czas przeszłości, odległej historii i czas współczesnego widza ery cyfrowej zdaje się upłynniać w jeden wspólny stan poza czasem, który zespala na krótki ośmiominutowy moment refleksji jaźń widza współczesnego z widzem historycznym. Pomiędzy nimi jest masa, układ nieregularnej abstrakcji, przepływający przez świadomość i ekran, by za pośrednictwem odmętu efektu obrazowego, niczym w swoistej ektoplazmie, pomóc nam przenieść się do innego wymiaru, gdzie czas i miejsce nie mają znaczenia w obliczu ponadczasowej ludzkiej wrażliwości na piękno i miłość.

Fabio Scacchioli

Film Miss Candace Hilligoss' Flickering Halo (2011) to krótki found footage Fabia Scacchiolego, którego materiał wyjściowy - podobnie jak w przypadku Morrisona - oparty jest na jednym filmie fabularnym $z$ historycznej epoki kina. Tym razem artysta spośród niezliczonych możliwości wyboru skupił się na pełnym metrażu Herka Harveya Karnawat dusz z roku 1962.

Do materiału znalezionego Scacchioli podszedł skrupulatnie i konsekwentnie, tworząc własną wersję filmu, „pulsującą” w trzynastominutowym skrócie. Z pozoru nieistotne źródło filmowe dla

[3] Ibidem, s. 134. 
współczesnego odbiorcy eksperymentu audiowizualnego to starannie przemyślany wybór Scacchiolego. Karnawał dusz to bowiem jeden z nielicznych niezależnych, kultowych filmów lat 6o. z gatunku horroru psychologicznego, gdzie głównym bohaterem jest kobieta.

Co wydaje się charakterystyczne w dziele Harveya, to aktywna, niezależna protagonistka, silnie wyemancypowana kobieta o ugruntowanych poglądach i fachowym zawodzie. Mimo swej zdecydowanej postawy cierpi na nerwice i lęki, które coraz silniej manifestują się w niesprecyzowanych odczuciach i wizjach, co ostatecznie prowadzi ją ku pozornie tragicznemu końcowi, a w istocie stanowi zaskakująca puentę wyjaśniającą pierwszą scenę filmu. Otóż protagonistka Mary, jak się dowiadujemy na końcu filmu, ginie w wypadku samochodowym w pierwszej scenie, a cały film to jej schizofreniczna przeprawa ku uzmysłowieniu sobie, że odtąd znajduje się w innej rzeczywistości, miejscu gdzie trwa wieczny karnawał dusz. Dla ówczesnego widza nie tylko postać Mary, ale i konstrukcja fabularna wraz z jej onirycznym przebiegiem, mogła stanowić niemałe zaskoczenie oraz ciekawe doświadczenie filmowe. Niestety, jeden z najsłynniejszych faktów dotyczących filmu to jego niedocenienie przez widownię podczas skromnej premiery. Doczekał się uznania dopiero po latach, gdy został wskrzeszony w systemie VHS i rozpropagowany wśród domowych widzów.

Odważna praca Scacchiolego stanowi multimedialną interpretację ugruntowującą pozycję niedocenionego dzieła Harveya, nadając mu awangardowy charakter oraz reinterpretując warstwę zarówno obrazową, jak i znaczeniową filmu. W swej formie Miss Candace... łączy kilka technik eksperymentalnych. Poza oczywistym użyciem strategii found footage twórca włączył w wymowę realizacyjną efekt migotania, bliski zabiegom strukturalistów, którzy działania na materiale przeprowadzali w drugiej połowie lat 6o. Scacchioli podjął się również względem pierwowzoru cyfrowych zniekształceń obrazu, multiplikacji nakładanych na siebie ujęć lub ich wycinków[4].

Posługując się kilkoma scenami z filmu Karnawał dusz, pracował nad każdą klatką oddzielnie. Montował je ze sobą, dodatkowo manipulując tempem każdego elementu ruchu w kadrze. Z obsesyjną powtarzalnością powielał określone atomy konkretnego ruchu, by za chwilę wyciąć jego część w akcie syntetyzującego montażu. Owym manipulacjom akompaniuje eksperymentalna muzyka elektroniczna Vincenza Core, która nieregularnymi dźwiękami oraz silnymi rytmicznymi powtórzeniami, gęsto rozmieszczonymi w procesualnym postępie muzyki, idealnie dopełnia obraz. Wizja i fonia zazębiają się, tworząc jedność halucynacyjnej wizji.

Reżyser opisuje Miss Candace..., odwołując się do pojęcia światła, które pokonuje przestrzeń z określoną prędkością. Czas, którego potrzebuje na dotarcie do naszego oka, jest zmienny, trudny do określenia.

[4] Multiplikacja z nakładaniem na siebie powstałych obrazów do wspólnej kompozycji była znana i często stosowana jako superimposition w latach 6o. i 70. przez amerykańskich awangardowych filmowców. 
W konsekwencji zawsze oglądamy przeszłość, nigdy teraźniejszość. Pomiędzy nami a naszym obrazem rzeczywistości jest dystans podobny do tego, który znajduje się między myślą a artykulacją. Właśnie ta przerwa, która zarówno separuje, jak i łączy, cisza pomiędzy słowami, pusta przestrzeń pomiędzy kadrami, to elementy stanowiące inspirację dla formy filmu[5]. Ze stwierdzeniem Scacchiolego ciekawie koresponduje pogląd Hugo Münsterberga, który interesował się operacjami mentalnymi nie tylko z poziomu twórców, protagonistów filmowych kreacji, ale i tym, które towarzyszyły ich odbiorowi. Dla teoretyka ostatecznym celem filmu jest ukazanie emocji. Umysł w bezpośrednim rozumieniu stanowi surowy materiał dla filmu, a zadaniem formy filmowej jest odzwierciedlenie emocji, wydobycie faktów mentalnych. Medium należy do sfery umysłu, zatem nie technika/technologia leży u jego podstaw, a operacje mentalne[6].

Widz Miss Candace... usytuowany jest w samym środku ostrych cięć, dzięki czemu za pośrednictwem aparatu percepcyjnego może doświadczyć w przełożeniu na własne, indywidualne doświadczenie, tego, co stało się udziałem filmowej Mary. Scacchioli dał mu odczuć fizycznie oraz mentalnie[7] poczucie osaczenia, opóźnienia reakcji w stosunku do bodźców, dezintegracji kodów symbolicznych tradycyjnego kina, poprzez zastosowanie środków filmowych/kreacyjnych powołanych do sterowania uwagą oraz wrażliwością widza na kilku poziomach.

Peter Tscherkassky

Kolejny rozdział historii kina zaanektowany pod trawestacyjne potrzeby found footage reprezentuje film Sidneya J. Furie Istota (1982), a reżyserem lokującym go w nowym kontekście kulturowym poprzez multimedialne przekształcenia jest Peter Tscherkassky, autor Outer Space (2000). Podobnie jak w filmie Harveya, oś narracji przebiega wzdłuż losów bohaterki, mającej kontakt z siłami nadprzyrodzonymi. W filmie Istota nie jest to jednak przekroczenie granicy pomiędzy światem żywych i umarłych, ale brzemię prześladowań ze strony nieczystej, niezmaterializowanej siły.

Kulturowy kontekst filmu $\mathrm{z}$ udziałem Barbary Hershey zasadza się na pewnych określonych kliszach sprzyjających rozwojowi niezwykle popularnych w okresie lat 8o. filmów z gatunku thriller erotyczny, horror-dramat psychologiczny. Istota eksploatuje temat kobiecej seksualności w jej brutalnych i niekonwencjonalnych przejawach w otoczce uzasadnienia dramaturgicznego o psychologicznych proweniencjach. I tak główna bohaterka jest ofiarą nasilających się ataków ze strony bezosobowej siły, która w coraz brutalniejszy sposób narusza jej intymność, dopuszczając się fizycznych ataków oraz gwałtów w domu kobiety. Tym bestialskim przejawom seksualnych praktyk unaocznionych widzowi

[5] Miss Candace Hilligoss' Flickering Halo, <http:// www.goodshortfilms.it/en/country/italy/miss-candace -hillligoss-flickering-halo> [dostęp: 6 stycznia 2015]. [6]D.J. Andrew, Główne teorie filmu, przeł. A. Kołodyński, PWSFTviT, Łódź 1995, s. 33.
[7] Fizycznie oraz mentalnie zarówno z poziomu tradycyjnego odbioru przekazu filmowego, jak i fizjologicznego poziomu odbioru formy ujętej postprodukcyjnymi manipulacjami. 
towarzyszy wątek psychologiczny, stanowiący konflikt pomiędzy protagonistką a jej synem, kochankiem oraz psychologiem, którzy nie dowierzają jej historii, nakreślając jednocześnie swój stosunek do zjawiska ukrytej agresji oraz wiarygodności kobiety w obliczu kompleksowego problemu, któremu należałoby się zdecydowanie przeciwstawić.

Na poziomie kulturowo-społecznego rozrachunku z epoką utajonej fetyszyzacji kobiecego ciała i seksualności lat 8o. film Tscherkasskiego stanowi wyraźną krytykę filmowych konstruktów podtrzymujących taki status kobiety-protagonistki w kinie. Odwołując się do koncepcji Laury Mulvey, przedstawionej w tekście Przyjemność wzrokowa a kino narracyjne, można by zaniepokoić się o kondycję widza w danym schemacie podziału ról pomiędzy bohaterów a zapośredniczonego w akcie montażu widza jako dodatkowego uczestnika narracji. Najważniejszy jest tu sposób przedstawienia kobiety w filmie, wplątanej w konwencje dotyczące diegezy,

[...] które wiążą się ze spojrzeniem. Spojrzeniem widza w bezpośrednim, skopofilicznym kontakcie z postacią kobiecą, ukazaną ku jego satysfakcji (i będącą wyrazem męskich oczekiwań), oraz spojrzeniem widza zafascynowanego obrazem swego sobowtóra, który porusza się w przestrzeni niby-naturalnej i za którego pośrednictwem widz zdobywa kobietę w diegezie[8].

W przypadku Istoty należy zdać sobie sprawę, że owym sobowtórem widza byłaby nieodczuwalna osobom postronnym filmowa siła, emanacja brutalnej energii seksualnej z sukcesem roszczącej sobie prawa do ciała oponującej i zdewastowanej tymi praktykami kobiety.

Tscherkassky, podobnie jak omawiani wyżej autorzy, wyszedł w swym eksperymencie audiowizualnym od zakupienia kopii filmu na taśmie $35 \mathrm{~mm}$, by następnie dokonać jej skanu cyfrowego, pozwalającego na dalsze manipulacje materiałem. Interpretacja represyjnego widma, zacieśniającego spiralę osaczenia wokół Carli (Barbara Hershey), jest u Tscherkasskiego wizją jeszcze bardziej mroczną. Poprzez pieczołowicie wybrane i skopiowane detale, wydobyte ze scen Istoty, wysuwa on na pierwszy plan materiałowy charakter swojego dzieła [9], zacierając jednocześnie fabularny charakter pierwowzoru. Sprowadzony do minimum wątek prześladowanej kobiety łączy się z materialnym charakterem medium filmowego. Celuloid przestaje być płótnem dla materii filmowej i wraz z postępem przebiegu Outer Space agresywnie reaguje na to, co dzieje się $\mathrm{z}$ Carlą/Barbarą uwięzioną wewnątrz filmowego kadru. Tscherkassky zespala poziomy ontologiczne świata przedstawionego na ekranie $\mathrm{z}$ jego materiałowym aspektem, tworząc $\mathrm{z}$ nich obraz składający się $\mathrm{z}$ nawet siedmiu warstw nakładanych na siebie w montażu[10].

[8] L. Mulvey, Do utraty wzroku. Wybór tekstów, red. i wstęp K. Kuc, L. Thompson, tłum. J. Murczyńska, Korporacja Ha!art, Kraków - Warszawa 2010, s. 41. [9] Strategia podobna do działań formalnych oraz ujęcia techniki found footage z Miss Candace Hilligoss' Flickering Halo Scacchiolego.
[10] <http://cleojournal.com/2013/11/28/attacked-by-nothing-barbara-hershey-and-the-entity-in-peter-tscherkasskys-outer-space-and-dream-work/> [dostęp: 6 stycznia 2015]. 
Obietnica nowego porządku w dekonstrukcji
Dzięki procesowi rozkładu świata narracyjnego Istoty oraz wdrożeniu filmowego aparatu jako ponaddiegetycznego uczestnika wydarzeń filmowych Tscherkassky zwrócił uwagę na istotę medium jako aktywnego partycypanta przemian społecznych z zupełnie innej sfery ontycznej. Maszyna przekazu, źródło informacji, technologiczne przedłużenie zmysłów ludzkich to cichy, ale gwałtowny i zdecydowany dominator, narzucający stechnicyzowanemu światu kierunek rozwoju, który z całą pewnością postępować będzie pod jego egidą. Na tym poziomie odczytania wchodzimy we współczesny problem cywilizacyjny człowieka przechodzącego głębiej w scyfryzowane uniwersum od epoki ekranów do epoki sieci, interaktywnego, zapośredniczonego uczestnictwa. Kobieta/Carla/Barbara to współczesny człowiek zdominowany przez tę bezosobową siłę.

Najnowsze realizacje found footage odbiegają wyraźnie od swoich międzywojennych protoplastów. Wraz z upływem czasu i powiększaniem się zasobu doświadczeń zarówno widzów, jak i twórców filmowych wymowa filmów opartych na materiałach znalezionych coraz silniej zasadza się na rozbijaniu klisz kulturowych zadzierzgniętych przez kinematografię oraz przyzwyczajeń percepcyjnych widza. W pracach Morrisona, Scacchiolego oraz Tscherkasskiego silnie wyczuwalny jest nowo-medialny dekonstrukcjonizm, który poprzez rozszczepienie schematu tekstualnego na czynniki pierwsze zespala go ponownie w świeże doświadczenie audiowizualne, możliwe do odczytania na kilku poziomach interpretacyjnych przez czujnego widza, wyszkolonego w odbiorze bardziej „dotkliwych” percepcyjnie środków formalnych. Podążając za myślą Andrzeja Gwóździa na temat „przemian zachodzących w całościowym dyskursie mediów w związku z odmiennymi konfiguracjami widzenia spajającymi w jedno odbiorcę, przestrzeń widzenia i samo medium" [11], można dojść do wniosku, jak immersyjne w dzisiejszych czasach jest doświadczenie filmowe i jak doskonale na poziomie środków filmowych i wyrazu ideowego wywiązali się ze swojego zadania omówieni twórcy. 